\title{
Waste cooking oil logistics and environmental assessment for biodiesel production in Cali
}

Evaluación ambiental y logística de la producción de biodiesel a partir de aceite usado de cocina en Cali

\author{
Angie Nathalia Benavides ${ }^{1}$ and Jairo Alexander Lozano-Moreno ${ }^{2 *}$ \\ ${ }^{1}$ Semillero de Investigación en Ingeniería Industrial, Universidad Autónoma de Occidente. Cll 25 \# 115-85, km 2 Vía Cali-Jamundi. C.P. \\ 760030. Cali, Colombia. \\ ${ }^{2}$ Grupo de Investigación en Competitividad y Productividad Empresarial (GICPE), Universidad Autónoma de Occidente. Cll 25 \# $115-85$, \\ km 2 Vía Cali-Jamundi. C.P. 760030 . Cali, Colombia.
}

\section{ARTICLE INFO:}

Received September 22, 2017

Accepted May 10, 2018

\section{KEYWORDS:}

Biomass, biodiesel, MILP, sustainable development

Biomasa, biodiesel, MILP, desarrollo sostenible
ABSTRACT: The present article analyzes different strategies for collecting Waste Cooking Oil (WCO) to produce biodiesel in Santiago de Cali. The quantitative and qualitative analysis of the models found in the literature highlighted the main characteristics for developing a WCO collection model considering the local parameters. Initial results showed that there is not enough WCO to satisfy the demand. However, an improved scenario is proposed following a supply point's densification strategy. The improved scenario not only fulfills the plant's installed capacity but also achieved WCO collection cost of 695.5 COP per gallon. 304 gallons of biodiesel could be produced with the collected WCO achieving a potential reduction of $230.81 \mathrm{~kg}$ of $\mathrm{CO}_{2}$ if this biodiesel is used to replace the same amount of diesel in the market, due to the difference between the $\mathrm{CO}_{2}$ emissions factor of diesel $\left[\mathrm{kg} \mathrm{CO}_{2} /\right.$ diesel gal] and biodiesel [kg CO2/biodiesel gal].

RESUMEN: En el presente artículo se analizaron diferentes estrategias para la recolección de Aceite de Cocina Usado (ACU) con el fin de utilizarlo como materia prima para la producción de biodiesel en Santiago de Cali. El análisis cuantitativo y cualitativo de los modelos encontrados en la literatura arrojó las principales características a tener en cuenta en la construcción y parametrización de un modelo de recolección de AUC, para este estudio de caso. Los resultados iniciales mostraron que no existen suficiente ACU para satisfacer la demanda. Sin embargo, se propone un escenario mejorado considerando una estrategia para la densificación del radio de suministro, logrando no solo la satisfacción de la capacidad instalada sino también costos de recolección de 695,5 COP por galón de AUC. Una producción de 304 galones de biodiesel puede lograrse con el AUC recolectado junto con una reducción potencial de $230,81 \mathrm{~kg}$ de $\mathrm{CO}_{2}$ si este biodiesel es usado para reemplazar la misma cantidad de diésel en el mercado.

\section{Introduction}

The Waste Cooking Oil (WCO) must be properly disposed after three utilizations in order to avoid health problems [1]. However, the current situation is far from suitable. From one side, there is an informal sector in Colombia, which collects the WCO in order to restore its transparency using unappropriated methods, repackage it and later sell it in low-income areas in big cities.

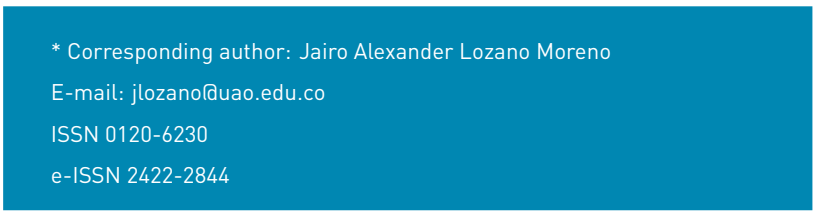

This illegality generates a series of negative impacts on public health, due to reusing cooking oil increases the cholesterol, causes cancer, attacks organ cells, produces intestinal problems, among others [2].

Furthermore, the beneficial components of cooking oil known as CIS (beneficial fats for good cholesterol) change to TRANS (fats considered harmful to cardiovascular health), which are hard to digest and eliminate, but also reducing good cholesterol and increasing bad cholesterol [3]. The prefix "cis" indicates that the functional groups are on the same side of the carbon chain; while in the "trans" prefix, the functional groups are on opposing sides of the carbon chain. On the other hand, the WCO is disposed through the sewage system due to the people's lack of knowledge or poor environmental awareness. Siphoning WCO generates several negative impacts in the 


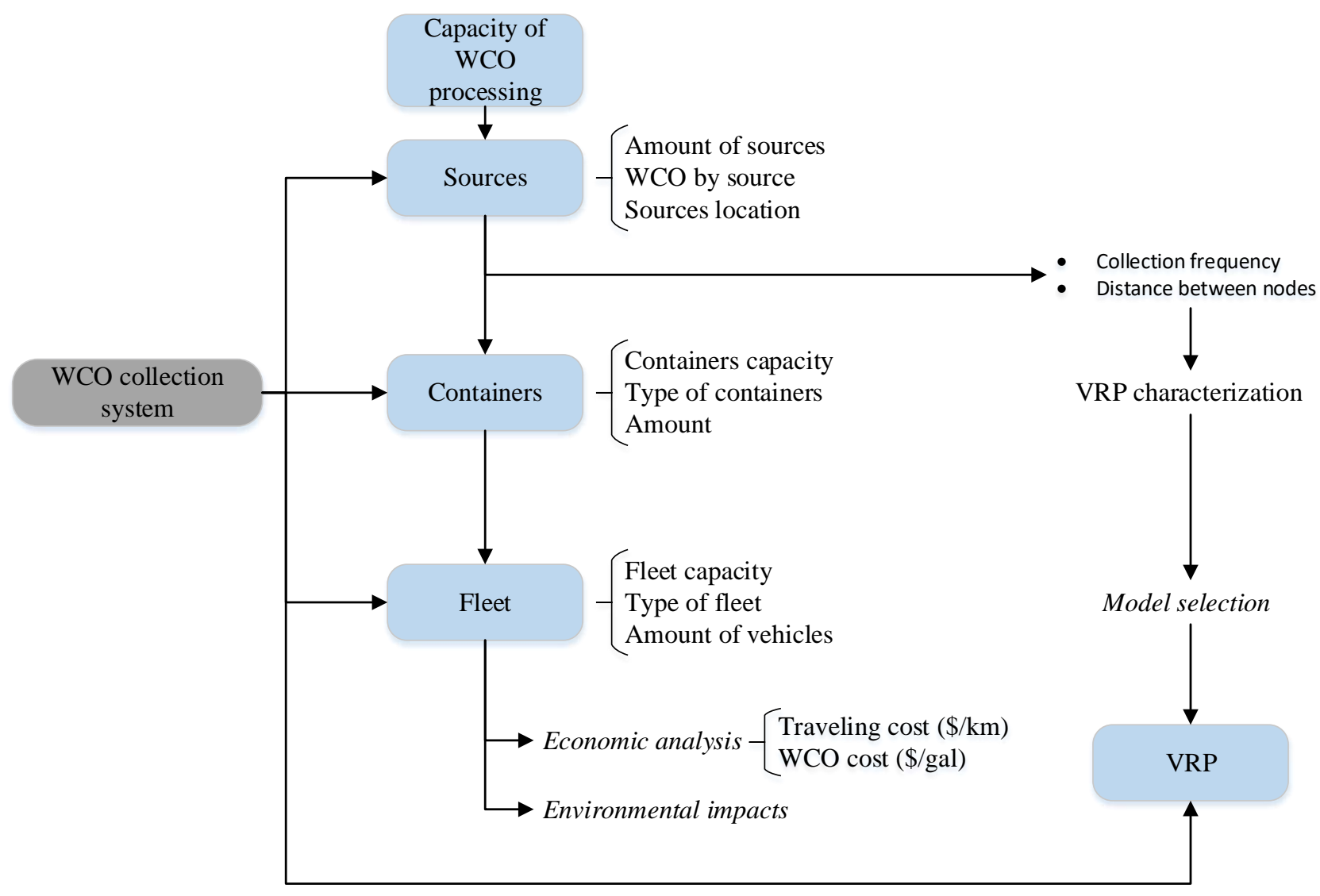

Figure 1 Conceptual model

environment such as the contamination of water sources and soil; pipe clogging and extra operational expenses in the wastewater treatment plants.

The success of the WCO-to-biodiesel production systems relies on the WCO collection efficiency, the conversion technology. The biomass supply chain models have been widely studied in the literature. [4] addressed the WCO collection system as a Multi-Depot Vehicle Routing Problem with Mixed Closed and Open Inter-Depot Routes and proposed a mixed integer linear programming (MILP) formulation where capacity and duration constraints are considered. The model's outputs were the vehicle routes where a reduction of $13 \%$ on mileage and $11 \%$ on fleet hiring cost were achieved compared with the current company solution. [5] designed a robust WCO-for-biodiesel supply chain under WCO supply and price as well as biodiesel demand and price uncertainties. First, a model without uncertainties was proposed for economic (profit), environmental (carbon emission), and social luncollected WCOl optimization. Second, a robust model was proposed by describing the main uncertainties as several uncertain scenarios. Finally, a genetic algorithm was applied to solve the robust model by dividing the model into several submodels through horizontal decomposition. As the main conclusion, the study remarks both robustness and sustainability as key factors in the biofuel supply chain design stage. The results suggest a decentralized production: loading was reduced by $0.64 \%-31.03 \%$ and transport by $8.31 \%-42.68 \%$. Better social effects could be reached if government policies are implemented allowing environmental and social cooperation from biorefineries.

Following a systems approach, [6] reviewed the operation mechanisms of third party take-back and biodiesel enterprise take-back modes in three countries and compared them using recycling costs and profits of biodiesel enterprises, subsidies for manufacturers, recycling rates, degree of administrative control, technical support and incentive mechanisms provided for the WCO suppliers. The study shows that the WCO-to-biodiesel conversion efficiency depends on the recycling mode that is being practiced, e.g., the third party take-back mode (practiced in Japan and the US) is superior to the biodiesel enterprise take-back mode due to the subsidies provided for biodiesel enterprises and the implementation of strict regulation policies in place for the restaurants. 
In the case of Colombia, there is a regulation stimulating biofuels production but there is not any kind of subsidies of regulation for the WCO management [1].

Moreover, [7] compared two WCO collection systems based on the energy efficiency to produce biodiesel: the results showed that it is feasible to collect WCO and waste lubricating oil according to the cost benefit analysis. [8] proposed two different solutions using Mixed Integer Linear Programming (MILP) formulations (PM: Primary Model and SM: Schedule-based Modell. Both formulations were compared in a case study and a partial linear relaxation was used showing better optimal results with the first model. The authors obtained a periodic routing schedule to repeat over an infinite horizon to calculate the amount of oil to collect, the total inventories and the collection total cost minimized. In another study, [9] evaluated two WCO collection systems in Portugal: door to door and using street containers. Depending on the collection system, the environmental effects can change. The street containers system environmental effects are less than $5 \%$ and the door to door system was close to $50 \%$, the difference in the results with the application of different allocation methods ranged between 1 to $11 \%$ (absolute value). [10] proposed a WCO-to-biodiesel supply chain design on three levels: sources, distribution centers and factories. They used a MILP model with environmental and economic optimization.

The state-of-the-art evidences that the WCO collection strategies varies in each country or study case. The use of MILP is common to measure economic, environmental or social impact. A collecting strategy for WCO in Cali becomes an alternative not only to reduce the social and health issues but also to know the environmental and economic impacts of biodiesel production.

\section{Methodological approach}

The Biomass supply chain models' key variables and characteristic were summarized from the state-of-the-art and process through a conceptual model with the aim of identifying the qualitative and quantitative factors (Figure 1). The models proposed by $[8,5]$ and $[10]$ were selected after the literature review. The three models were analyzed considering their main objective and the conceptual model proposed. This characterization led to select the methodology proposed by [8] with a decentralized strategy where the WCO is collected door to door (in situ). Although it is possible to get this kind of result through the models proposed by [10], they were not selected because their model took into consideration the whole biodiesel supply chain, i.e., the biorefineries, the WCO collection and the biodiesel distribution system, which are beyond the scope of the current paper. In addition, the MILP formulation and model will be adjusted bearing in mind the Supply Points (SPs), WCO frequency, containers' features, vehicle capacity and another local characteristic in Santiago de Cali.

\subsection{Mathematical formulation}

The model parametrization was done taking into consideration the local features around the WCO SP and the sustainable development policy proposed for the study. The objective function is to minimize the total cost (TC) of collecting the WCO necessary to satisfy the plant demand as is shown in the Equation (1).

$$
\begin{gathered}
\text { Min TC }=c \sum_{\mathrm{i} \in \mathrm{I}} \sum_{\mathrm{j} \in \mathrm{I},(\mathrm{j} \neq \mathrm{i})} \sum_{t \in T} d_{i j} * X_{i j t}+v \sum_{i \in I C} \sum_{t \in T} X_{0 i t}+h \sum_{t \in T} I_{0 t} \\
\sum_{j \in I, j \neq i} F_{i j t}-\sum_{j \in I, i \neq j} F_{j i t}=W_{i t}, \quad \forall i \in I C, \quad \forall t \in T
\end{gathered}
$$

$F_{i j t} \leq\left(Q-a_{i j}\right) X_{i j t}, \quad \forall i \in I, \quad \forall j \in I, \quad \forall t \in T, \quad i \neq j$

$F_{i j t} \leq Q-W_{j t}, \quad \forall i \in I, \quad \forall j \in I C, \quad \forall t \in T, \quad i \neq j$

$$
F_{i j t} \geq W_{i t}-A_{i}\left(1-X_{i j t}\right),
$$

$\forall i \in I C, \quad \forall j \in I, \quad \forall t \in T, \quad i \neq j$

$$
\sum_{j \in I, j \neq i} X_{j i t}=Y_{i t}, \quad \forall i \in I C, \quad \forall t \in T
$$

$$
\begin{gathered}
\sum_{j \in I, j \neq i} X_{i j t}=Y_{i t}, \quad \forall i \in I C, \quad \forall t \in T \\
\sum_{i \in I C} X_{i 0 t}=\sum_{i \in I C} X_{0 i t}, \quad \forall t \in T \\
W_{i t} \leq A_{i} Y_{i t}, \quad \forall i \in I C, \quad \forall t \in T \\
I_{i t} \leq A_{i}\left(1-Y_{i t}\right), \quad \forall i \in I C, \quad \forall t \in T \\
I_{i t}=I_{i t-1}+a_{i t} Z_{i}-W_{i t}, \quad \forall i \in I C, \quad \forall t \in T \\
I_{i 0}=I_{i \tau}, \quad \forall i \in I \\
I_{0 t}=I_{0 t-1}+\sum_{i \in I C} W_{i t}-r_{t}, \quad \forall t \in T
\end{gathered}
$$


Table 1 Model parameters

\begin{tabular}{lll}
\hline Parameter & Description & Units \\
\hline $\mathbf{C}$ & Traveling cost per unit distance (variable costs) & COP/km \\
$\mathbf{d}_{\mathbf{j}}$ & Asymmetric distance from node $i$ to node $j,(i, j \in I)$. & $\mathrm{km}$ \\
$\mathbf{a}_{\mathbf{i t}}$ & Waste vegetable oil accumulation amount in period $t$ at node $i,(i \in I C, t \in T)$. & $\mathrm{gal}$ \\
$\mathbf{r}_{\mathbf{t}}$ & Waste oil requirement of the company per period, $t \in T$. & $\mathrm{gal}$ \\
$\mathbf{h}$ & Inventory holding cost per period for storing one gallon oil at the depot. & COP/d \\
$\mathbf{V}$ & Operating cost per vehicle per day (fixed costs) & $\mathrm{COP} / \mathrm{d}$ \\
$\mathbf{Q}$ & Vehicle capacity in gallons. & $\mathrm{gal}$ \\
$\mathbf{A}_{\mathbf{i}}$ & Total weekly accumulation of waste oil at node $i,(i \in I C)$ & $\mathrm{gal}$ \\
\hline
\end{tabular}

Table 2 Decision variables

\begin{tabular}{lll}
\hline Variable & Description & Units \\
\hline $\mathbf{X}_{\mathbf{i j t}}$ & Binary variable indicating if $\operatorname{arc}(i, j)$ is traversed by a vehicle in period $t,(i, j \in I, t \in T)$. & - \\
$\mathbf{Y}_{\text {it }}$ & Binary variable indicating if node i has been visited in period $t,(i \in I C, t \in T)$. & - \\
$\mathbf{Z}_{\mathbf{i}}$ & Binary variable indicating if node i has been visited at least once during a cycle $(i \in I C)$. & - \\
& It attains the value 0, if node $i$ is not visited at all. & \\
$\mathbf{F}_{\mathbf{i j t}}$ & The amount of waste oil flow from node $i$ to node $j$ in period $t,(i, j \in I, t \in T)$. & gal \\
$\mathbf{W}_{\mathbf{i t}}$ & The amount of waste oil collected from node $i$ in period $t,(i \in I C, t \in T)$. & gal \\
$\mathbf{I}_{\mathbf{i t}}$ & Ending inventory of waste oil by the end of period $t$ at node $i,(i \in I, t \in T)$. & gal \\
$\mathbf{I}_{\mathbf{i} \mathbf{0}}$ & Initial inventory of waste oil at the beginning of the cycle at node $i,(i \in I)$. & gal \\
\hline
\end{tabular}

$$
\begin{aligned}
& Z_{i} \leq \sum_{t \in T} Y_{i t}, \quad \forall i \in I C \\
& Z_{i} \geq Y_{i t}, \quad \forall t \in T \\
& Q \sum_{i \in I C} X_{0 i t} \geq \sum_{i \in I C} W_{i t}, \quad \forall t \in T \\
& Q\left(\sum_{i \in I C} X_{0 i t}-1\right)+1 \leq \sum_{i \in I C} W_{i t}, \quad \forall t \in T \\
& X_{i j t} \in\{0,1\} \quad \forall i \in I, \quad \forall j \in I, \quad \forall t \in T, \quad i \neq j \\
& Y_{i t} \in\{0,1\} \quad \forall i \in I C, \quad \forall t \in T \\
& Z_{i} \in\{0,1\} \quad \forall i \in I C \\
& F_{i j t} \geq 0, \quad \forall i \in I, \quad \forall j \in I, \quad \forall t \in T, \quad i \neq j \text { (21) } \\
& W_{i t} \geq 0, \quad \forall i \in I C, \quad \forall t \in T \\
& I_{i t} \geq 0, \quad \forall i \in I, \quad \forall t \in T \\
& I_{i 0} \geq 0, \quad \forall i \in I
\end{aligned}
$$

Subject to: Constraint (12) represents the flow balance at each source node and the constraints (3) and (4) their upper bounds following the vehicle capacity and the waste oil quantity collected on each node. Lower bounds are set by the constraints (5). (6) and (7) are the incoming and outgoing degree balance constraints to couple the binary $X_{i j t}$ and $Y_{i t}$ variables; which are complemented by the depot's degree balance throughout constraint (8). Constraints (9) ensure that the collection amount at node $\mathrm{i}$ in period t must be zero unless it is visited in that period. Constraints (10)-(15) are used to calculate the inventory at the source nodes and the depot. Inequalities (16) and (17) guarantee that the number of vehicles dispatched is enough to carry the collected WCO. (18) to (24) define the binary variables and the non-negative constraints.

Table 1 and Table 2 summarize the model parameters and variables respectively.

The minimum cost and the vehicle routes obtained from the model will be complemented adding environmental and operational indicators with the aim of analyzing the different impacts generated by the system as well as its efficiency.

\subsection{Performance indicators}

A set of performance indicators are proposed broadening the model scope. Currently, there is not reliable information about the WCO collection costs, the GHG emissions or potential GHG reductions due to the WCO-based biodiesel use. Table 3 summarizes the 
Table 3 Model performance indicators

\begin{tabular}{|c|c|c|}
\hline Indicator & Formula & Units \\
\hline \multicolumn{3}{|l|}{ Economic: } \\
\hline$\overline{\text { Total inventory holding costs }}$ & & COP \\
\hline Traveling costs & & $\mathrm{COP} / \mathrm{km}$ \\
\hline Vehicle operating costs & & $\mathrm{cOP} / \mathrm{d}$ \\
\hline Total cost & & $\mathrm{COP}$ \\
\hline $\begin{array}{l}\text { Cost per WCO gal collected } \\
\text { Operational: }\end{array}$ & $\complement=T C / v$ & COP/WCO gal \\
\hline $\begin{array}{l}\text { Biodiesel produced from WCO } \\
\text { Total distance } \\
\text { Environmental: }\end{array}$ & $\begin{array}{l}B=v * \lambda \\
\mathrm{d}_{T}\end{array}$ & $\begin{array}{l}\text { gal } \\
\mathrm{km}\end{array}$ \\
\hline $\begin{array}{l}\mathrm{CO}_{2} \text { emissions from } \mathrm{WCO} \text { collection } \\
\text { Potential reduction of } \mathrm{CO}_{2}\end{array}$ & $\begin{array}{l}\Upsilon=d_{T} * \omega * \Delta \\
\beta=\delta *(\rho-\mu)\end{array}$ & $\begin{array}{l}\mathrm{kgCO}_{2} \\
\mathrm{kgCO}_{2}\end{array}$ \\
\hline
\end{tabular}

Table 4 Results for the case study with modified requirements

\begin{tabular}{ll}
\hline Amount of WCO collected & Day 1: $23.79 \mathrm{gal}$ \\
& Day 2: $40.21 \mathrm{gal}$ \\
& Total: $64 \mathrm{gal}$ \\
& 11 of 12 \\
& 2 (one per day) \\
& Day 1 (1 route): $0-1,1-2,2-3,3-0$ \\
Total routes & Day 2 (1 route): $0-1,1-4,4-5,5-7,7-8,8-9,9-10,10-11,12-0$ \\
& 8.21 WCO gal \\
Initial inventory at the depot & 8.21 WCO gal \\
Final inventory at the depot & 8.21 WCO gal \\
The depot's maximum inventory &
\end{tabular}

Table 5 Performance indicators for the case study with modified requirements

\begin{tabular}{ll}
\hline Indicator & Value \\
\hline Economic: & $129.71 \mathrm{COP} / \mathrm{d}$ \\
\hline Total inventory holding costs & $2,878.33 \mathrm{COP} / \mathrm{km}$ \\
Traveling costs & $58,869 \mathrm{COP} / \mathrm{d}$ \\
Vehicle operating costs & $61,877 \mathrm{COP}$ \\
Total cost & $966.83 \mathrm{COP} / \mathrm{WCO} \mathrm{gal}$ \\
Cost per WCO gal collected* & \\
Operational: & $52.09 \mathrm{gal}$ \\
Biodiesel produced from WCO & Day $1: 17 \mathrm{~km}$ \\
Total distance & Day $2: 54.28 \mathrm{~km}$ \\
& \\
Environmental: & $12.51 \mathrm{~kg} \mathrm{CO}$ \\
CO $\mathrm{CO}_{2}$ emissions from $\mathrm{WCO}_{2}$ collection & $39.58 \mathrm{~kg} \mathrm{CO}$ \\
\hline Potential reduction of $\mathrm{CO}_{2}$ & \\
\hline
\end{tabular}

${ }^{*}$ Crude palm oil in Colombia: 1,968 COP (second semester 2017)

proposed performance indicators. Where $C$ is the cost per WCO gal collected, TC is the total cost [COP] and $v$ is the WCO collected [WCO gal]. $B$ is the biodiesel produced from WCO collected, and $\lambda$ is the WCO-to-biodiesel production ratio of 0.8 [biodiesel gal/WCO gal]. $\gamma$ is the $\mathrm{CO}_{2}$ emissions from WCO collection; $d_{T}$ is the total distance traveled [km]; $\omega$ is the vehicle performance [gasoline gal/km] and $D$ is the $\mathrm{CO}_{2}$ emissions factor [kg
$\mathrm{CO}_{2} /$ gasoline gal]. $\beta$ is the potencial reduction of $\mathrm{CO}_{2}$; $\delta$ is the biodiesel produced from WCO [gal]; $\rho$ is the $\mathrm{CO}_{2}$ emissions factor [ $\mathrm{kg} \mathrm{CO}_{2} /$ diesel gallon] and $\mu$ is the $\mathrm{CO}_{2}$ emissions factor [ $\mathrm{kg} \mathrm{CO}_{2} /$ biodiesel gal]. 
Table 6 Results for the improved collection n system

\begin{tabular}{|c|c|}
\hline Amount of WCO collected & $\begin{array}{l}\text { - Day 1: } 155.51 \mathrm{gal} \\
\text { - Day 2: } 148.49 \mathrm{gal} \\
\text { Total: } 304 \mathrm{gal}\end{array}$ \\
\hline Number of nodes visited & 44 of 52 \\
\hline \multirow[t]{10}{*}{ Total routes } & 7 \\
\hline & - Day 1 ( 4 route): \\
\hline & Route 1: $0-4,4-21,21-41,41-10,10-11,11-17,17-0$ \\
\hline & Route 2: $0-6,6-7,7-22,22-27,27-28,28-32,32-34,34-44,44-0$ \\
\hline & Route 3: $0-8,8-9,9-12,12-13,13-15,15-16,16-18,18-26,26-0$ \\
\hline & Route 4: $0-52,52-24,24-25,25-29,29-30,30-38,38-0$ \\
\hline & - Day 2 (3 routes): \\
\hline & Route $1: 0-1,1-5,5-7,7-9,9-19,19-20,20-4,4-6,6-24,24-33,33-34,34-35,35-38,38-0$ \\
\hline & Route 2: $0-3,3-22,22-26,26-31,31-42,42-2,2-0$ \\
\hline & Route 3: 0-37, 37-46, 46-47, 47-50, 50-39, 39-40, 40-41, 41-44, 44-0 \\
\hline Depot's initial inventory & O WCO gal \\
\hline Depots' final inventory & O WCO gal \\
\hline Depot's maximum inventory & 3.81 WCO gal \\
\hline
\end{tabular}

Table 7 Performance indicators for the improved collection system

\begin{tabular}{ll}
\hline Indicator & Value \\
\hline Economic: & \\
\hline Total inventory holding costs & $60.20 \mathrm{COP}$ \\
Traveling costs & $5,331.55 \mathrm{COP} / \mathrm{km}$ \\
Vehicle operating costs & $206,041.71 \mathrm{COP} / \mathrm{d}$ \\
Total cost & $211,433.46 \mathrm{COP}$ \\
Cost per WCO gal collected & $695.50 \mathrm{COP} / \mathrm{WCO} \mathrm{gal}$ \\
& \\
Operational: & \\
\hline Biodiesel produced from WCO & $304 \mathrm{gal}$ \\
Total distance & Day 1: $186.67 \mathrm{~km}$ \\
& Day 2: $197.85 \mathrm{~km}$ \\
& \\
Environmental: & \\
CO & \\
Potential reduction of $\mathrm{CO}_{2}$ & $42.40 \mathrm{~kg} \mathrm{CO}$ \\
\hline
\end{tabular}

Table 8 Comparison between scenarios

\begin{tabular}{lccc}
\hline & Current & Improved & Ideal \\
\hline WCO collected [gal/d] & 32 & 152 & 1100 \\
Max. biodiesel produced [gal/d] & 32.67 & 126.35 & 893.75 \\
Installed capacity used & $3.65 \%$ & $13.82 \%$ & $100 \%$ \\
\hline
\end{tabular}

\section{Results and discussion}

A pilot plant located in Cali was taken as a case study in order to validate the model. The plant has an installed and a fleet capacity of $1100 \mathrm{WCO}$ gal/d $\left(r_{t}\right)$ and 50 gal (Q) respectively. The current system has 12 supply points (I) with an average $W C O$ production of $0,83 \mathrm{gal} / \mathrm{d}\left(a_{i t}\right)$. The WCO collection will be twice per week $(T)$.

\subsection{Current system}

The model was run with the 64-bit version of the mathematical modeling and optimization suite GAMS 23.6.5, conducted on a server equipped with Intel Core i5 $2.40 \mathrm{GHz}$ y $3 \mathrm{~GB}$ RAM. The optimization did not reach any feasible solution as the requirements were higher than the WCO available in the system (33.58 gal). Even though a feasible solution could be obtained if the plant 
purchases virgin oil; this is against the model's sustainable development policy. Then, the plant demand was adjusted to the current WCO availability in the system with the aim of validating the model and obtains an optimal. The model results and performance indicators are summarized in Table 4 and Table 5 respectively.

The model's results scheduled the vehicle routes for the two days programmed. An optimal total cost and WCO collection of $61.877 \mathrm{COP}$ and $966.83 \mathrm{COP} / \mathrm{WCO}$ gal was calculated. The environmental indicators allow knowing the carbon footprint generated by the WCO collection, and the potential $\mathrm{CO}_{2}$ reduction if the WCO-based biodiesel is used to replace the same amount of diesel in the market.

\subsection{SPs densification (improved scenario)}

A different approach to attack the problem is increasing the WCO availability using a SPs densification strategy. The goal is to have a greater WCO collection in order to profit from the plant's installed capacity. The SPs densification was done adding WCO sources following the existing point's profiles, i.e., adding others restaurants, casinos, universities within the supply radius. The results obtained with this strategy are shown in Table 6 and Table 7.

The strategy evidences an important effect in the amount of WCO collected and the biodiesel produced. It is possible to satisfy the plant installed capacity if the extra SPs are considered, despite the higher total costs; the cost per WCO gal collected is reduced by $28 \%$. The environmental indicators showed a significant improvement with $\mathrm{CO}_{2}$ reductions five time better than the initial scenario.

Table 8 shows a comparison between the analyzed scenarios (current and improved) together with the pilot plant installed capacity (ideal scenario). Each scenario offers enhanced results, but social strategies of knowledge appropriation must be developed to include the community and changes in WCO collection practices.

\section{Conclusions}

The study of WCO-to-biodiesel supply chain models has been widely covered by the literature. Nevertheless, there are not local studies with information about the WCO costs or other logistics indicators.
A MILP model was proposed to calculate the minimum collection cost and set the vehicles routes. A logistic and environmental assessment was presented to evaluate the feasibility of WCO-based biodiesel production in Cali considering qualitative and quantitative factors. The sustainable WCO-based biodiesel production is possible in Cali if social strategies targeting changes in WCO disposal practices are implemented with the goal of increasing the collection system's efficiency through the SPs densification.

\section{Index sets}

$I=0,1, \ldots, n$ : the set of $n$ source nodes and the depot 0 . $I C=1, \ldots, n$ : the set of $n$ source nodes only la subset of $I$ ).

$\mathrm{T}=1, \ldots, \mathrm{T}$ : the set of $\mathrm{T}$ periods in the cyclic planning horizon.

\section{References}

[1] J. Echavarría, “El desarrollo sostenible y el reciclaje del aceite usado de cocina a la luz de la jurisprudencia y el ordenamiento jurídico colombiano," Producción + limpia, vol. 7, no. 1, pp. 109-122, 2012.

[2] ASOGRASAS. (2017) asograsas. Accessed Jan. 31, 2017. [Online]. Available: http://www.asograsas.com/

[3] Concejo de Bogotá. (2012). [Online]. Available: http://www. alcaldiabogota.gov.co/sisjur/normas/Norma1.jsp?i=45921

[4] T. R. Pereira, M. I. Gomes, and A. P. Barbosa, “Planning waste cooking oil collection systems," Waste Management, vol. 33, no. 8, pp. 1691-1703, Aug. 2013.

[5] Y. Zhang, Y. Jiang, M. Zhong, N. Geng, and D. Chen, “Robust optimization on regional WCO-for-Biodiesel supply chain under supply and demand uncertainties," Scientific Programming, vol. 2016, no. 1, pp. 1-15, Jan. 2016.

[6] H. Zhang, A. Ozturk, Q. Wang, and Z. Zhao, “Biodiesel produced by waste cooking oil: Review of recycling modes," Renewable and Sustainable Energy Reviews, vol. 38, pp. 677-685, Oct. 2014.

[7] A. Singhabhandhu and T. Tezuka, "Prospective framework for collection and exploitation of waste cooking oil as feedstock for energy conversion," Energy, vol. 35, no. 4, pp. 1839-1847, Apr. 2010.

[8] D. Aksen, O. Kaya, F. S. Salman, and Y. Akca, "Selective and periodic inventory routing problem for waste vegetable oil collection," Optimization letters, vol. 6, no. 6, pp. 1063-1080, Aug. 2012.

[9] C. Caldeira, J. Queirós, and F. Freire, "Biodiesel from waste cooking oils in portugal: alternative collection systems," Waste and Biomass Valorization, vol. 6, no. 5, pp. 771-779, Oct. 2015.

[10] Y. Jiang and Y. Zhang, "Supply chain optimization of biodiesel produced from waste cooking oil," Transportation Research Procedia, vol. 12, pp. 938-949, 2016. 